\title{
References
}

Martinez, P.: "Première détection européene amateur de la comète de Halley", L'Astronomie, 1985 June, p.281

Martinez, P.: "L'utilisation du T 60 pour la redécouverte des comètes périodiques", L'Astronomie, 1987 May, p.247

Merlin, J.C.: "La redécouverte des comètes périodiques" in Astronomie - le Guide de l'Observateur, Paris, 1987, pp.417-20

[See also the paper by C. Buil on the use of CCDs - Eds.]

\section{Shape and Frequency of Outbursts of P/Schwassmann-Wachmann 1}

J.C. Merlin, D. Fayard, and E. Gérard

17 rue $P$. Mendès-France, F-71200 Le Creusot, France

\begin{abstract}
Observations made since the comet's discovery (1927) were analyzed and reduced to remove observational bias. Comparison was made with possible mechanical effects on the nucleus (tidal forces, impacts). The observations appear to best fit an internal mechanism (exothermic chemical reactions) as proposed by Whipple.
\end{abstract}

[The text of this paper was received, but was of such extreme length that it could not be included in full, as the author requested. - Eds.]

\section{Astrometry of Comet Halley}

Hadi Hadavi Biruni Observatory, Shiraz University, Shiraz 71454, Iran

[This contribution was delivered, but neither text nor abstract have been received. Eds.]

\section{Observation and Analysis of Comet Tails}

\section{R.L.W. van de Weg}

von Hemskerkstraat 29, NL-7622 JG Borne, Netherlands

\begin{abstract}
Details of $\mathrm{H}_{2} \mathrm{O}$ and dust production in $\mathrm{P} / \mathrm{Halley}$ are mainly derived from amateur observations of cometary tails, leading to a gas/dust mass-ratio. The rotational period (2.21 day) is also found from amateur observations. Velocity and acceleration of the plasma and velocity and direction of the solar wind are also derived, together with size and indications of the mass-distribution function for dust particles.
\end{abstract}

